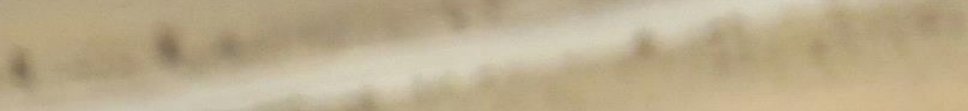

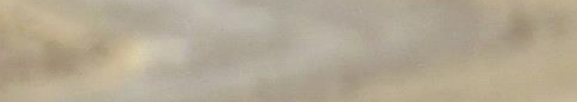

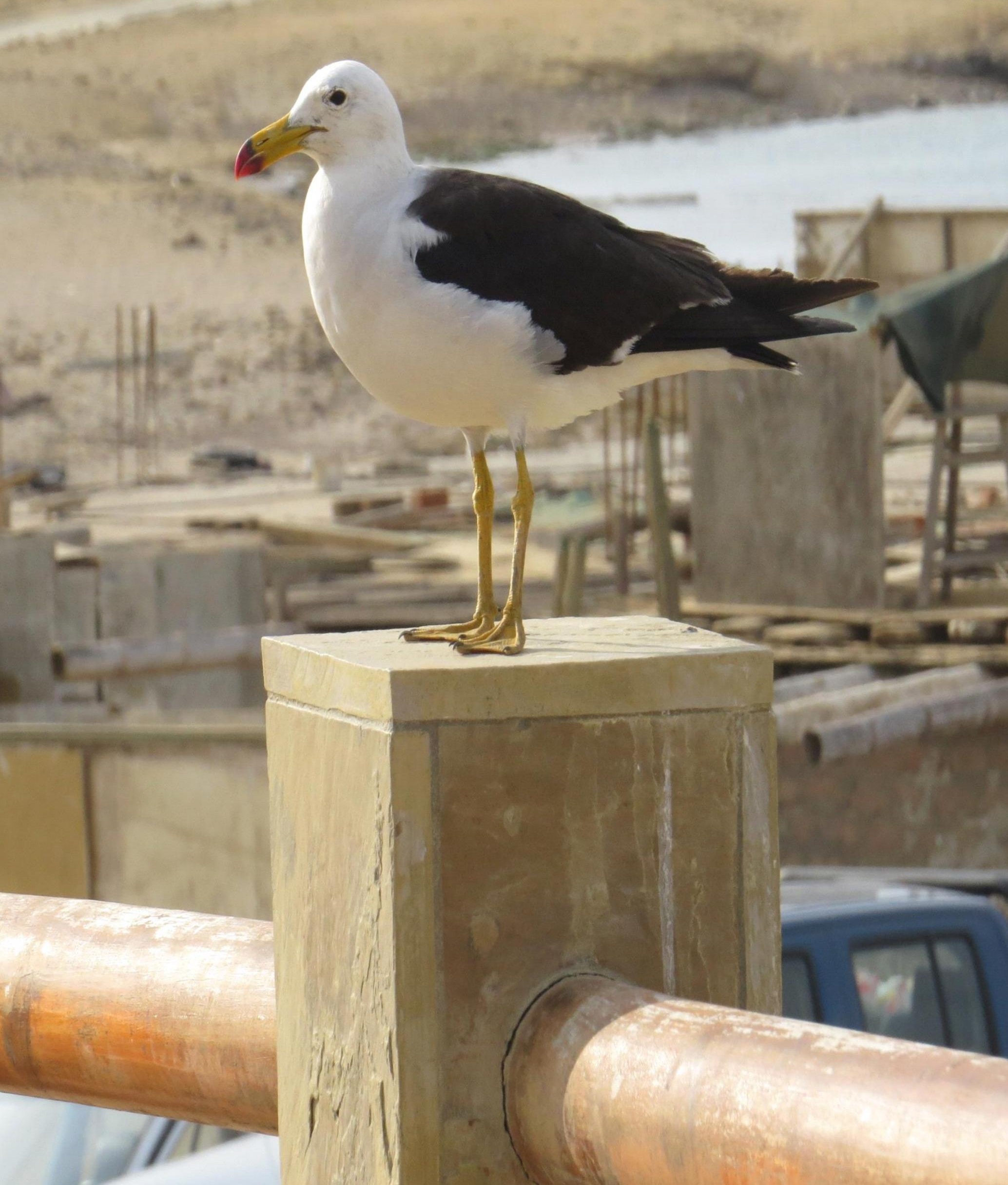




\title{
PERIFERIZAÇÃO URBANA E NEGLIGÊNCIA AO PATRIMÔNIO- TERRITORIAL DE DIAMANTINA (MG)
}

\author{
URBAN PERIPHERIZATION AND NEGLIGENCE ON THE TERRITORIAL-HERITAGE \\ OF DIAMANTINA (MG)
}

\author{
Vitor João Ramos Alves ${ }^{1}$ \\ Uliane Cristina dos Santos Borges ${ }^{2}$
}

\begin{abstract}
Resumo:
O presente artigo propõe, por meio de uma abordagem dialética, de tipo qualitativa, analisar o movimento de periferização e a negligência ao patrimônio-territorial no município de Diamantina (MG), tendo como estudo de caso o Bairro da Palha, localizado a $4 \mathrm{~km}$ do centro histórico tombado pela Unesco e porta de entrada da conhecida "Rota do ouro e do diamante". Pôde-se observar que o bairro pesquisado se desenvolveu e consolidou por meio de uma ocupação urbana caracterizada por recorrentes processos de segregação socioespacial, intensificada pelas ações conjuntas do poder público ao tombamento do centro histórico, que contribuíram para uma negligência ao patrimônio-territorial do bairro e das áreas periféricas de Diamantina (MG) em sua totalidade.
\end{abstract}

Palavras-chave: Periferização urbana. Patrimônio-territorial. Bairro da Palha. Diamantina (MG).

\begin{abstract}
:
This article proposes, by means of a dialectic approach, of qualitative type, to analyze the movement of urban periphery and the negligence of the patrimony-territorial in the municipality of Diamantina (MG), having as case study the Bairro da Palha, located $4 \mathrm{~km}$ from the historical center overturned by Unesco and gateway to the known "Gold and Diamond Route". It were observed that the research district developed and consolidated by means of an urban occupation characterized by recurring processes of sociospatial segregation, intensified by the joint actions of the public power to the tipping of the historical Center, Which contributed to a negligence on the territorial patrimony of the neighborhood and the peripheral areas of Diamantina (MG).
\end{abstract}

Key-words: Urban peripherization. Territorial-heritage. Bairro da Palha. Diamantina (MG).

\section{INTRODUÇÃO}

Com mais de três séculos de fundação, passando de povoado a arraial até chegar a município, Diamantina, no Estado de Minas Gerais, é uma cidade rica em história e tradições, intrinsecamente ligada à exploração do ouro e do diamante. O conjunto arquitetônico do centro histórico da cidade foi tombado pelo Instituto do Patrimônio Histórico e Artístico Nacional (IPHAN),

\footnotetext{
${ }^{1}$ Doutorando pelo Departamento de Geografia da Universidade de Brasília - GEA/UnB. Mestre em Turismo pelo Centro de Excelência em Turismo - CET/UnB. Graduado em Turismo pelo Instituto de Educação Superior de Brasília - IESB. E-mail: vitorjoaoramosalves@gmail.com

${ }^{2}$ Mestranda pelo Departamento de Geografia da Universidade Federal de Goiás - UFG - Regional Catalão. Graduada em Geografia pela Universidade Federal de Goiás - UFG - Regional Catalão. E-mail: uli.cris@hotmail.com
} 
em 1938, e, no final da década de 90, veio a ser reconhecido mundialmente como Patrimônio Cultural da Humanidade, pela Organização das Nações Unidas para a Educação, a Ciência e a Cultura (UNESCO).

Considerado um dos bairros de ocupação mais antigos de Diamantina, o Bairro da Palha é originário do final do século XIX, pela lógica do garimpo e de seu papel para o adensamento populacional no município. Ao longo do século XX, houve um aumento da ocupação clandestina na cidade, que se massifica durante a crise da mineração do diamante, a qual promoveu uma migração populacional do campo para áreas mais urbanizadas, incluindo o território da Palha. Também conhecido como o local onde tinha construída a Chácara de Chica da Silva, observa-se no Bairro da Palha um aumento dos impactos paisagísticos e da perda de referenciais geográficos e de memória da cultura popular por atividades de ocupação espacial de comunidades segregadas pelo centro histórico.

Nesse contexto, o presente trabalho propõe, por meio de uma abordagem dialética do tipo qualitativa, analisar o movimento de periferização e a negligência ao patrimônio-territorial, pelo capital, no município de Diamantina, tendo como estudo de caso o Bairro da Palha, localizado a $4 \mathrm{~km}$ do centro histórico tombado.

Toma-se como objetivos da pesquisa: (i) identificar como se dá o processo de periferização urbana no Bairro da Palha, em Diamantina; (ii) verificar as formas de negligência ao patrimônioterritorial lá existentes e suas implicações ao território; e por fim (iii) analisar, particular e universalmente, as consequências provocadas pelo processo de periferização urbana e da negligência ao patrimônio-territorial, a partir do sujeito autóctone, elencando possíveis proposições.

Foram utilizadas como fontes de dados as pesquisas bibliográfica e empírica, esta última realizada no município no dia 05 de maio de 2018. Durante a permanência em campo, foram feitos registros fotográficos atuais e entrevistas com os moradores do bairro pesquisado, as quais possibilitaram chegar à análise e às considerações finais do presente trabalho.

Reconhecendo a periferização urbana como uma violenta forma de segregação socioespacial e a negligência aos patrimônios-territoriais, como forma de predomínio da colonialidade do poder, buscou-se compreender as razões desses processos em Diamantina, a fim de contribuir para uma preservação da memória local, identificando-a como patrimônio-territorial, e fortalecer a resistência contra o movimento da modernidade e avanço do capital na localidade.

\section{PERIFERIZAÇÃO URBANA NO BAIRRO DA PALHA (MG)}

A grande expansão urbana no Brasil é considerada recente e foi proporcionada a partir de mudanças estruturadas pela economia e pela organização da sociedade a partir da década de 1930 . 
Tal expansão das cidades brasileiras se deu de forma dispersa e fragmentária o que implicou e implica até hoje em novas organizações do espaço. Durante vários séculos o Brasil foi considerado um país eminentemente agrário anterior ao processo de industrialização, no entanto, tal processo desempenhou um papel importante, e no caso das cidades históricas o período do ciclo do ouro foi primordial para urbanização e expansão de seus territórios.

Segundo Costa (2015, p. 400) poucos são os estudos que revelam como se deu a formação dos bairros de Diamantina. Desde os anos de 1860 a cidade já era considerada como um dos centros de comércio mais ativos em todo o estado de Minas Gerias, que surgiu, cresceu e se consolidou devido à dinâmica ligada a atividade de extração de Diamantes. Desse modo o setor de serviços também se desenvolveu de forma significativa a partir do impulso e da dinâmica da extração na região diamantífera durante o ciclo do ouro.

Segundo Martins (apud COSTA, 2015, p. 402) "a chegada dos trilhos de ferro e a inauguração da estação ferroviária, propiciou o encurtamento das distâncias, facilitou o escoamento das produções e a consolidação da cidade frente ao mercado regional". O avanço dessa malha ferroviária deu início então à chegada da modernização na região central do Brasil. As fábricas de tecidos, ainda para Costa (2015, p. 400) dinamizaram os novos fluxos de capital, de mercadorias e de pessoas a partir dos anos de 1920; e juntamente com ela, serviços para a fabricação de chapeis, cortes de couro e lapidação de diamantes, e assim a cidade se estabeleceu e se consolidou como um importante entreposto comercial.

No entanto, a temporada de glória em Diamantina estendeu-se apenas até metade do século XIX, quando alguns fatores foram decisivos para estagnação da atividade econômica na cidade, como as facilidades que as rodovias proporcionaram, onde Diamantina não conseguia mais disputar com o mercado exterior, restando como atividade, apenas o garimpo e a fábrica de tecidos. Mesmo com sua economia praticamente estagnada, a cidade servia como um polo atrativo para a população que procurava melhores condições de vida, essa circulação propiciou a formação das periferias em Diamantina.

A formação e periferização do Bairro da Palha, em Diamantina, originária então do final do século XIX, tem por lógica o garimpo e possui papel fundamental no adensamento populacional no município. Ao longo do século XX, houve um aumento considerável dessa ocupação clandestina que se massifica durante a crise da Mineração do Diamante, a qual promoveu uma migração populacional do campo para áreas mais urbanizadas.

Considerado como um dos bairros de ocupação mais antiga de Diamantina, o Bairro da Palha caracteriza-se inicialmente, conforme Costa (2015, p. 309), por uma segregação sócio-territorial produzida por uma força contra-hegemônica do próprio centro urbano, por representar locus de 
dependência diária da população - ou parte dela. Esse distanciamento social tem expressão no território e na paisagem citadina e expressa-se na estratificação urbana. Para Costa (2015, p. 388), ao mesmo tempo em que a segregação favorece uma homogeneidade de zonas distintas, como expressão espacial, permite a distinções sócio-qualiativas entre tais zonas.

Atualmente, a articulação do bairro em sua totalidade, conforme o zoneamento da Prefeitura Municipal, é de uso residencial e comercial local de alguns serviços, caracterizados como bom - regular. Tal distinção justifica-se devido à "distância" imposta em relação às centralidades comerciais. $\mathrm{O}$ bairro tornou-se menos dependente, materialmente, do centro urbano devido à "distância" imposta ou negligenciada para com a população, forçando-a a criar mecanismos de permanência e sobrevivência em seu próprio território.

A área do bairro, conforme o Plano Diretor de Diamantina, é caracterizada como residencial de nível III [predominância do uso; precário ou inexistente atendimento em lazer, educação e serviços; de médio a baixo padrão construtivo; ou, ainda, zona híbrida do "estilo patrimônio", na área de tombamento] com enclave de nível IV [predominância do uso; o "morar" se desempenha de forma não desejada e não própria para a vida digna; precário padrão construtivo]. A infraestrutura é caracterizada por frágil presença da municipalidade [alguns subsistemas de infraestrutura urbana].

Tessari e Braga (apud MARES, 2013, p. 4) refletiu a respeito da implantação de infraestruturas nas periferias "[...] os investimentos para esse fim podem levar certo tempo para sua aplicação, o que induz ao pensamento de que essas áreas são periféricas não só por sua localização ou condição econômica, mas também por sua posição na periferia das políticas públicas [...]". Assim, podemos refletir sobre a presença da municipalidade na periferia de Diamantina, principalmente no bairro estudado.

O Bairro da Palha é incluso também nas Zonas Espaciais de Interesse Social (ZEIS - áreas em que há o interesse público em ordenar a ocupação por meio de urbanização e regularização fundiária ou, ainda, implantar empreendimentos habitacionais de interesse social). Entretanto, conforme Costa $(2015$, p. 435), não foram identificadas ações no sentido de empreendimento habitacionais no bairro.

Ao contrário do que caracteriza as ZEIS, onde nas quais devem possuir moradias dignas, infraestrutura, equipamentos sociais, áreas verdes, o Bairro da Palha se caracteriza ao contrário, este corresponde a um dos mais carentes da cidade, e a visita in locus revelou a precariedade das residências, a frágil presença da municipalidade e/ou ausência de infraestrutura básica, como rede de esgoto (recém chegada ao bairro), quebra-molas, calçadas, transporte público e segurança, a precariedade também dos equipamentos para lazer, na educação, e nos serviços médicos no bairro. 
Em contraste com as residências do centro da cidade e até mesmo de bairros próximos ao estudado, há alguns casos em que a topografia irregular do terreno estimulou a construção de casas em áreas de encostas e de riscos que legalmente não devem existir e as casas antigas da Palha são caracterizadas por sua atual situação de precariedade, são desamparados tanto pelo poder público local e por financiadores para a preservação de tais residências. As casas que ainda resistem conforme a sua arquitetura originária, possuem uma infraestrutura precária e apresentam rachaduras nas paredes, trincas e infiltrações.

Figuras 1 e 2: Caracterização do Bairro da Palha em Diamantina (MG)

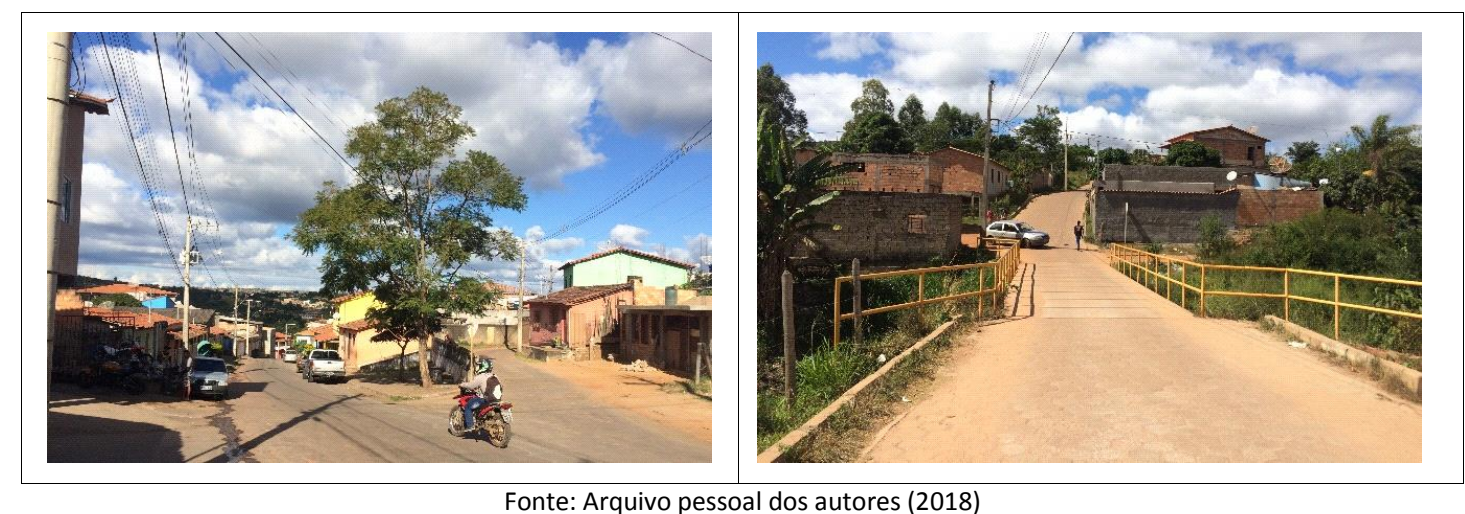

É evidente a necessidade da restauração e de preservação dessas casas e monumentos que correspondem à história e a identidade local das chamadas cidades históricas, conforme apresenta Maurício de Almeida Abreu (1998) em sua reflexão sobre a necessidade de recuperação, restauração e preservação das paisagens urbanas.

o passado das cidades brasileiras está sendo revalorizado e a preservação/recuperação/restauração do que sobrou das paisagens urbanas anteriores é um objetivo que vem sendo perseguido por inúmeros agentes, destacando-se aí os governos municipais. Mesmo cidades relativamente novas já adotam a prática de preservar os vestígios mais significativos de sua história. $\mathrm{E}$ naquelas em que a destruição da herança urbana foi devastadora, grandes têm sido os esforços para salvar e valorizar o que restou. Essas tentativas nem sempre têm sido bem sucedidas (ABREU, 1998, p. 83).

Infelizmente, tais políticas não apreciaram e não apreciam toda a cidade, restringindo essas ações apenas ao centro histórico de Diamantina, não considerando a cidade em sua totalidade. Assim, os bairros periféricos perdem partes da sua história e de sua identidade.

Ao observar que é na cidade, e principalmente no bairro, que existem as possibilidades de ações, de interação sócio-urbanas, de existir e resistir, torna-se importante salientarmos a importância dos espaços públicos, como as praças, os parques, e jardins, pois esses locais demonstram-se como importantes espaços de uso coletivo para a convivência, recreação e preservação da memória e da identidade local, porém a realidade da praça da Palha é angustiante, a academia ao ar livre (Figuras 3 e 4 ) instalada onde provavelmente seria essa única praça do bairro 
conta com aparelhos deteriorados recém pintados, com uma infraestrutura precária e a obra encontra-se inacabada.

Figuras 3 e 4: Caracterização do Bairro da Palha em Diamantina (MG

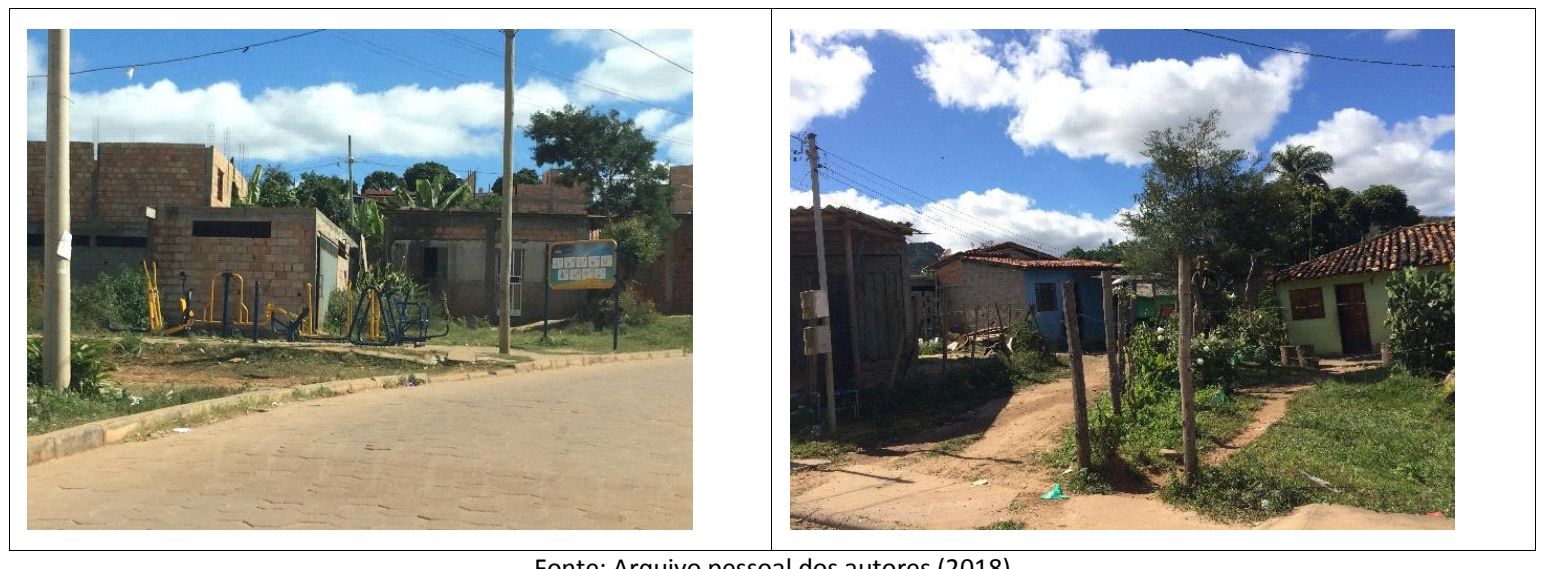

Fonte: Arquivo pessoal dos autores (2018)

A Unidade Básica de Saúde (UBS) do bairro (Figura 5) dispõe de um horário específico de funcionamento, das 07 às $17 \mathrm{~h}$ de segunda a sexta, e em casos de emergência os moradores devem se deslocar para a Santa Casa de Caridade ou Hospital Nossa Senhora da Saúde ambos localizados no centro da cidade. Há de se considerar que o transporte público no Bairro da Palha e em quase toda a Diamantina circula de duas em duas horas somente até as sete horas da noite e praticamente não funciona aos finais de semanas e feriados.

Apesar do Bairro da Palha contar com três escolas, uma estadual (Figura 6) que atende alunos do ensino fundamental e médio, uma municipal que atende alunos somente da educação infantil e uma segunda municipal que oferece vagas na educação infantil e ensino fundamental, é preocupante o número das evasões desses alunos principalmente nos últimos anos do ensino fundamental e no ensino médio, já que nenhuma das escolas contam com algum tipo de projeto no contra-turno escolar.

Figuras 5 e 6: Presença da municipalidade no Bairro da Palha (MG)

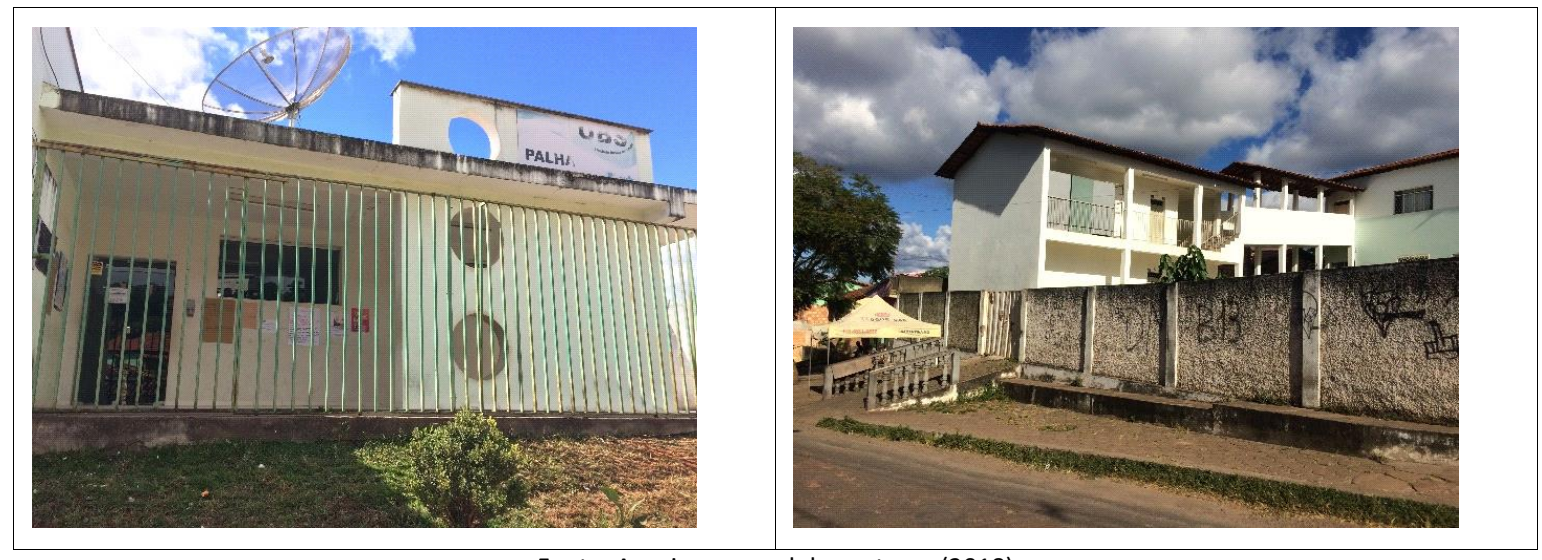

Fonte: Arquivo pessoal dos autores (2018) 
Podendo então ser considerada como uma municipalidade incipiente a encontrada no Bairro da Palha, na qual a população não é contemplada de forma efetiva, que garanta uma qualidade na saúde, na educação, no lazer e na segurança, que não contempla os saberes da população, bem como a sua cultura, os fazeres e a memória local. Apesar de a vida na periferia ser sofrida, ela possui um tempo diferente do centro e que apesar da população ser humilde em suas posses ela é rica em saberes, em força e esperança que não deveria e não deve ser ignorada pelo poder público.

\section{A NEGLIGÊNCIA AO PATRIMÔNIO-TERRITORIAL NO BAIRRO DA PALHA (MG)}

Ao buscar analisar o processo de negligência ao patrimônio-territorial no Bairro da Palha, em Diamantina (MG), faz-se necessário compreender o conceito do termo utilizado. Conforme Costa (2016) o patrimônio-territorial é definido como representativo dos elementos singulares da história registrada em símbolos territoriais resistentes à colonialidade do poder, tais como a arte, a religião, os saberes, os fazeres, os artesanatos de grupos subalternos urbanos e rurais, entre outros.

Tendo em vista que o patrimônio-territorial vai além do conceito de patrimônio histórico instituído, segundo Costa (2016), busca-se identificar os elementos materiais e imateriais do Bairro da Palha, os quais possuem um valor simbólico derivado da memória, dos usos e dos significados dados a estes pela população residente, em sua vida cotidiana. Tal patrimônio-territorial poderá passar desde uma reativação de festas e tradições para o consumo local, até a revalorização de construções representativas da memória do território historicamente marginalizado.

Como alertou Costa (2016), o patrimônio-territorial não pode ser imposto por terceiros, muito menos a sua forma de aproveitamento. A vontade da comunidade deve ser sempre respeitada, sob pena de colocar em risco a própria existência da cultura e identidade deste patrimônio. É a partir dela que o patrimônio-territorial é produzido e ganha sentido, e deve ser para ela, a comunidade, que o patrimônio-territorial deve se voltar.

\section{1 o patrimônio-territorial negligenciado do bairro da Palha (MG)}

A origem do Bairro da Palha, como já apresentado, é do final do século XIX, pela lógica do garimpo e de seu papel considerável no adensamento populacional do município de Diamantina. Ao longo do século $X X$, houve um aumento da ocupação territorial de forma clandestina que se massificou durante a crise da Mineração do Diamante, a qual promoveu uma migração populacional das áreas rurais para áreas mais urbanizadas do município, conforme já apresentado anteriormente.

De acordo com o relato do morador do bairro e guia local de turismo, Agnaldo Clemente (2018), o Bairro da Palha é conhecido, pela população, como porta de entrada do antigo Arraial do 
Tijuco, hoje Diamantina. Todos os viajantes que entravam no arraial antigamente tinham que passar pelo bairro. No período da Coroa Portuguesa, havia um posto de fiscalização no local, /que administrava o fluxo de quem chegava e saía do território diamantino, na tentativa de controlar a extração mineral e efetuar a cobrança de impostos. A partir desse movimento, a coroa estabeleceu a demarcação de todo o território em torno do Arraial do Tijuco.

Grinberg; Guinberg \& Almeida (2007), pontuaram sobre essa fase do território expondo que, nesse período, seis marcos foram cuidadosamente estabelecidos nas divisas do Tijuco e cerca de oito postos fiscais controlavam a entrada e a saída do local. O Distrito Diamantino era considerado como um Estado dentro de outro Estado (MG), com regras e leis distintas do resto da Capitania, submetido a uma administração especial: a Intendência dos Diamantes, com leis próprias e válidas somente no território do arraial.

É nesse contexto que surge a figura de Francisca da Silva de Oliveira, ou apenas Chica da Silva. Escrava, posteriormente alforriada, viveu no Arraial do Tijuco, durante a segunda metade do século XVIII. Manteve durante mais de quinze anos uma união consensual estável com o rico contratador dos diamantes João Fernandes de Oliveira, tendo com ele treze filhos. E foi no território, que hoje é chamado de Bairro da Palha, que o contratador João Fernandes de Oliveira construiu para sua esposa, uma chácara de veraneio que está presente na memória dos moradores até hoje.

As pesquisas revelam que não há registro fotográfico dessas construções denominadas Chácara da Chica da Silva. Apenas são encontrados relatos e narrativas a respeito, conforme o trecho a seguir, conforme discutiu Miranda (2016).

Na Chácara da Palha, logo além do aterro, à saída sul do Tijuco, antigo nome da cidade de Diamantina, João Fernandes ergueu uma casa de excelente construção, com a aparência de um castelo, rica e formosa capela e um teatro onde se encenava óperas e comédias. A chácara era cercada por agradáveis jardins, compostos de plantas decorativas, labirintos de roseiras entrelaçadas e arvoredos transplantados da Europa, em cujas sombras se sucediam trabalhos de água, como fontes, lagos, cascatas deslizando sobre arranjos de cristais e conchas (MIRANDA, 2016, p. 13).

A autora ainda apresenta que na chácara havia uma barreira de pedra que represava o riacho e dava origem a um grande tanque ou um pequeno mar. Nesse tanque, também foi construída, por engenheiros navais portugueses, uma nau de dimensões reduzidas com mastro, vela e armação. Guarnecida com uma tripulação de 10 homens que manobravam o pequeno navio, a embarcação foi construída para mostrar à Chica da Silva o que era um navio e o maquinismo que trouxera João Fernandes de Oliveira de Portugal, atendendo assim as curiosidades de sua esposa. Nas figuras a seguir pode-se observar o que restou do pequeno córrego que alimentava o "mar" onde foi construída a nau de Chica da Silva. 
Clemente (2018) ainda afirma que todos as edificações que faziam parte dessa antiga chácara foram destruídas com as ocupações. Eram casarões semelhantes aos que hoje são tombados pelo IPHAN e o reconhecido como a Casa da Chica da Silva, localizado no centro histórico de Diamantina.

Figuras 7 e 8: Antigo Córrego Pururuca, hoje chamado de Córrego da Palha.

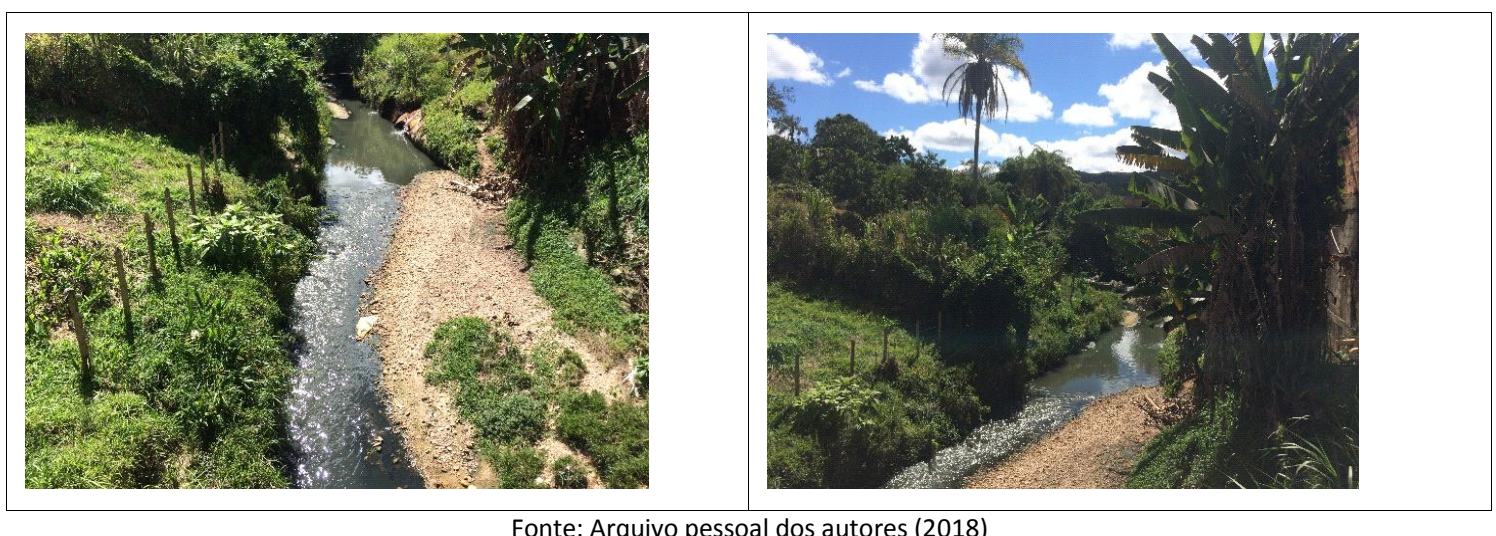

Alguns registros mostram ainda, complementa Clemente (2018), que, com a prisão de João Fernandes de Oliveira, quando em sua ida para Portugal, a Chácara da Chica da Silva foi parcialmente demolida e com as suas madeiras foi construída a Casa da Glória, outro patrimônio tombado no centro histórico da cidade. O restante do material da antiga casa foi utilizado na reconstrução das edificações próximas, pelos seus arrematantes, compostos pela família de Felício dos Santos. Quando houve o falecimento de Silvio Felício dos Santos, o antigo proprietário das terras, a Chácara foi invadida e saqueada até não restar mais nada.

As terras, onde estava construída a Chácara, diz o guia, foi ocupada pela população clandestinamente, transformando o território nos bairros que hoje recebem os nomes: Bairro da Palha e Bairro Maria Orminda (CLEMENTE, 2018). O pouco do que restou e ainda pode ser observado no local, das edificações da antiga chácara, $s$ apenas as colunas antigas que aparecem ao fundo das casas, conforme demonstrado nas figuras a seguir.

Clemente (2018) também relata que houve um descaso das autoridades públicas a esse respeito. Segundo o morador, elas deveriam ter tentado evitar a destruição da casa da Chácara, como esforço de preservar a memória do território. 
Figuras 9 e 10: Vestígios dos antigos casarões antigos denominados como Chácara da Chica da Silva

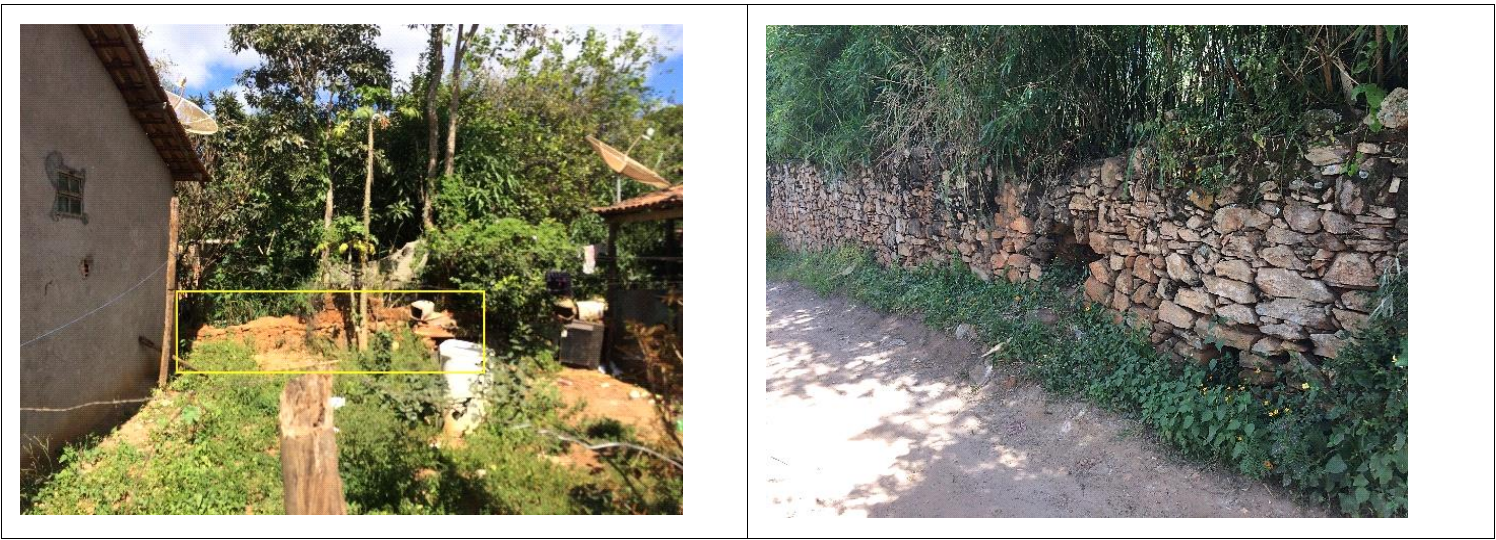

Fonte: Arquivo pessoal dos autores (2018)

Outros moradores também comentaram, durante as entrevistas realizadas, sobre a inexistência de trabalhos que pudessem resgatar a memória do Bairro da Palha, ou até mesmo que pudesse incentivar a realização de atividades que valorizassem ou restaurassem esses elementos significativos da história.

Nesses vinte e cinco anos de invasão da área, se perdeu muito da história do Bairro da Palha. Futuramente, a memória pode acabar. Ninguém trabalha essa parte histórica com os moradores. Eles sabem que era lugar de uma antiga casa da Chica da Silva, mas os jovens não aprendem nas escolas sobre essa história (CLEMENTE, 2018).

Além da sede da chácara, muitas muretas de pedras, construídas naquela época para cercar as principais residências da Chica, foram também destruídas. Havia uma lenda de que os escravos escondiam moedas de ouro dentro dessas muretas. Esse motivo acabou contribuindo para a destruição das edificações. "Se a prefeitura tivesse separado a área para estruturar um sítio arqueológico, iria encontrar muitos objetos históricos soterrados, sobre o registro da Chácara da Chica da Silva" (CLEMENTE, 2018).

Algumas moradoras também narraram sobre a existência de uma antiga mina d'água, próxima ao córrego da Palha, onde as mulheres se agrupavam para lavar roupa e conversar. Hoje essa mina também não existe mais, nem seus vestígios.

Outro ponto importante sobre a negligência ao patrimônio-territorial do bairro é a diminuição do número de casas coloniais, resistentes ao tempo, conforme apresentadas nas figuras a seguir. 
Figuras 11 e 12: Casas coloniais em processo de abandono e negligência pelos próprios moradores.

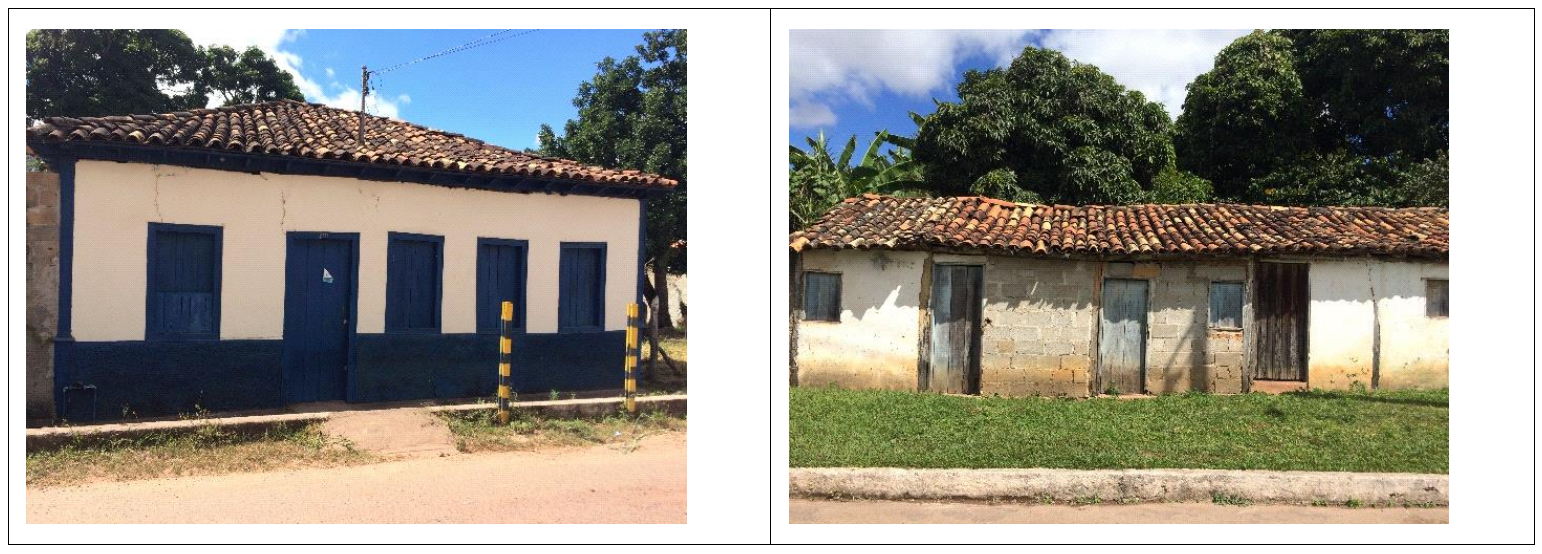

Fonte: Arquivo pessoal dos autores (2018)

Normalmente, essas casas são abandonadas e derrubadas para, logo em seguida, serem construídas outras residências de estética moderna, perdendo a característica e identidade de um bairro colonial. Tal mudança foi observada pelo registro realizado por Costa (2015) e que os pesquisadores puderam comprovar in loco a transformação ocorrida na estética da casa depois de oito anos.

Pode-se então perceber como o planejamento é instituído. Um planejamento setorizado, buscando ao mesmo tempo homogeneizar, mas que ao mesmo tempo impossibilita a manutenção das casas e dos bairros periféricos, usando os bens (material e imaterial) do centro histórico como uma mercadoria e não como identidade.

Figuras 13 e 14: Transformação estética das residências no Bairro da Palha.

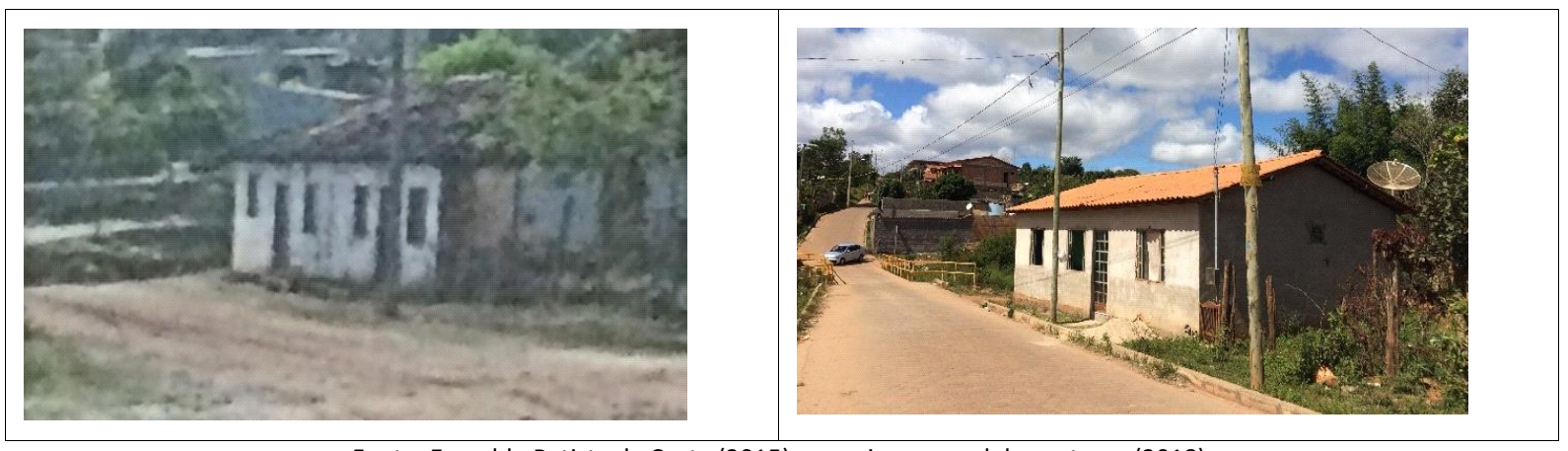

Fonte: Everaldo Batista da Costa (2015) e arquivo pessoal dos autores (2018).

A casa colonial apresentada na Figura 13 foi derrubada e construíram uma outra edificação, de projeto moderno sobre suas bases (Figura 14). O formato, completamente distinto da memória colonial do bairro, se destaca em sua totalidade nas residências do bairro.

Nas construções teóricas de Costa (2016), o patrimônio-territorial também é caracterizado como representativo dos elementos singulares da história, registrados em forma artística, religiosa e como modo de vida de grupos subalternos urbanos e rurais. Entretanto, os moradores do Bairro da 
Palha revelaram que não participam das atividades festivas e religiosas do centro histórico de Diamantina, mesmo em períodos de baixa presença de turistas na cidade. Acabam demonstrando uma relação de indiferença pela área tombada e promovem suas próprias festas.

Também foi identificado que os turistas que transitam pelo bairro, em busca da rota do ouro e do diamante, não têm contato direto com a população. Eles apenas passam para buscar os atrativos naturais presentes ao redor do bairro, como cachoeiras e a gruta do salitre, por exemplo.

De certo modo, a narrativa sobre a estrada real, conforme os relatos obtidos, não é importante para os moradores, pois eles não se beneficiam das atividades turísticas que acontecem em Diamantina, conforme já narrado. Uma das moradoras entrevistadas chegou a afirmar que seria possível resgatar a importância da Chácara da Chica da Silva e da mina d'água para a memória da formação do Bairro da Palha, mas que por questões de necessidades sociais, a população prefere investir em melhorias para o bairro, podendo até esquecer a memória patrimonial, a fim de melhorar a atual qualidade de vida dos moradores.

Da mesma forma, pôde ser percebido um receio da população em se abrir com os pesquisadores, por se considerarem em situação de risco e segregação social. Com receio de serem prejudicados, podendo perder a moradia onde vivem [que ainda não é legalizada devido a ocupação espacial clandestina da área], eles não revelam com muita facilidade outras informações sobre a história do bairro.

Por meio desses exemplos, foi possível evidenciar como as ações e práticas do poder público municipal promoveram, em atendimento aos interesses do capital, uma negligência ao patrimônioterritorial do bairro e, contrariamente, a manutenção de um planejamento urbano que contribuísse para intensificar a periferização das camadas populacionais de baixa renda.

\section{CONSIDERAÇÕES FINAIS}

O reconhecimento de Diamantina (MG) como lugar de expressões originais, de características arquitetônicas e sociais, promoveu a cidade mineira como, supostamente, diferente, diversificada, festiva e opulenta. Tal posicionamento promoveu o tombamento do centro histórico diamantinense, no ano de 1938, pelo IPHAN e, em fevereiro de 2002, a UNESCO deu-lhe o título de Patrimônio Cultural da Humanidade.

Reconhecendo a periferização urbana como uma violenta forma de segregação socioespacial e a negligência ao patrimônio-territorial, como forma de predomínio da colonialidade do poder, busca-se compreender as razões desses processos em Diamantina, a fim de contribuir para uma preservação da memória histórica local, reconhecida para esse trabalho como o patrimônio- 
territorial do Bairro da Palha, e fortalecer a resistência ao movimento da modernidade e ao avanço do capital no território mineiro.

Com a incipiente municipalidade e a consequente carência de recursos financeiros para os investimentos em infraestrutura e qualidade de vida da população do bairro, muitas práticas e ações públicas se traduzem na efetividade do espaço construído, tendo como consequência a negligencia ao patrimônio-territorial.

Considera-se a memória da Chácara da Chica da Silva, a mina d'água onde as mulheres se encontravam, a lenda dos escravos que escondiam moedas de ouro nas muretas da chácara, e os demais registros apresentados no capítulo dois desse artigo, como patrimônios-territoriais do Bairro da Palha, ou seja, elementos simbólicos derivados da memória coletiva de usos e significados dados ao bairro pela população residente, o que possibilita uma futura ativação patrimonial pelos próprios moradores.

A destruição de ruínas históricas para a construção de habitações, a alteração dos modos de vida tradicionais, a perda de referências geográficas e de memória da cultura popular do bairro, são alguns casos concretos de evidentes danos ao reconhecido patrimônio-territorial do bairro.

Entretanto, conforme apresenta Costa (2015, p. 452):

(...) a preservação e a democratização local dos bens culturais da humanidade requerem planejamento de bairros específicos e ações que partam desses mesmos bairros em sentido ao centro histórico, material e simbolicamente, o que representa o inverso das ações políticas (COSTA, 2015, p. 452).

Apesar de todos os posicionamentos aqui apresentados, não se pode deixar de identificar resistências ou saídas positivas entre a situação periférica do bairro e a negligência apresentada ao patrimônio-territorial [nele existente].

A vida cotidiana se faz presente no bairro, demarcando cultural e espacialmente a presença dos residentes, além de apontar registros significativos de um patrimônio-territorial, ainda a ser valorizado e ativado pela própria população. Assim, a busca pela preservação do patrimônio do Bairro da Palha deve estar em conjunto com uma difusão generalizada das possibilidades de empoderamento dos bens culturais pela população, associadas às políticas urbanas de melhoria para o bairro, voltadas ao sujeito e não ao mercado capitalista.

O esforço deve ser o de fazer a população local se apropriar da história do bairro, vinculadas às políticas urbanas, a fim de buscar o empoderamento e a democratização do patrimônio, pela implantação de acesso, à compreensão ou a justificativa das localizações e às possibilidades de mobilidade entre o bairro e o centro histórico de Diamantina. Portanto, observa-se que as questões da preservação do patrimônio-territorial do Bairro da Palha estão intrinsecamente relacionadas com a posição social do sujeito que lá reside, o que exige uma reformulação das políticas urbanas 
vigentes, a fim de reverter o processo de periferização e enfrentar a negligência ao patrimônioterritorial lá existente.

\section{REFERÊNCIAS}

ABREU, Maurício de Almeida. Sobre a Memória das cidades. Revista da Faculdade de Letras Geografia I (pp. 77-97), 1998.

BERDOULAY, V. \& ENTRIKIN, N. Lugar e Sujeito perspectivas teóricos . In: Marandola, E. H., Qual o espaço do lugar? Geografia, Epistemologia e Fenomenologia (pp. 93-116). Brasil: Perspectivas, 2012.

CLEMENTE, Agnaldo. Entrevista realizada em 5 de maio de 2018. Diamantina (MG), 2018.

MEIRA, E. J. Contos de Diamantina. In: A Chacára de Chica da Silva. Disponível em: $<$ https://contosdediamantina.webnode.pt/news/a-chacara-da-chica-da-silva/>. Acessado em: 25 de maio de 2018.

COSTA, Everaldo Batista. Cidades da patrimonialização global: simultaneidade totalidade urbana totalidade mundo. São Paulo: FAPESP, 2015.

Utopismos patrimoniais pela América Latina: resistências à colonialidade do poder. XIV Coloquio Internacional de Geocrítica. Las utopías y la construcción de la sociedad del futuro (2016, pp. 1-32).Disponível em: <http://www.ub.edu/geocrit/xiv_everaldo costa.pdf $>$. Acessado em: 28 de abril de 2018.

GRINBERG, K., GUINBERG, L. \& ALMEIDA, A. C. Para conhecer: Chica da Silva. Rio de Janeiro: Jorge Zahar, 2007.

INSTITUTO DO PATRIMONIO HISTÓRICO E ARTÍSTICO NACIONAL. In: Portal Iphan. Disponível em: $<$ http://portal.iphan.gov.br/uploads/ckfinder/arquivos/Centro\%20Hist\%C3\%B3rico\%20de\%20Diama ntina.pdf>. Acessado em: 10 de junho de 2018.

MARES, R. M. A periferia pobre e a produção do espaço urbano: O caso de Vitória da Conquista/BA. II Simpósio de Estudos Urbanos: A dinâmica das cidades e a produção do espaço. Disponível em: <http://www.fecilcam.br/anais/ii_seurb/documentos/mares-rizia-mendes.pdf>. Acessado em: 14 de Agosto de 2013.

MIRANDA, A. Xica da Silva: a cinderela negra. Rio de Janeiro: Record, 2016.

PREFEITURA MUNICIPAL DE DIAMANTINA. Disponível em: <Erro! A referência de hiperlink não é válida.>. Acessado em: 01 de Junho de 2018.

. História de Diamantina. Disponível em: <http://diamantina.mg.gov.br/o-municipio/historiade-diamantina/>. Acessado em: 01 de Junho de 2018.

RAYEL, R. S. \& GUIMARAES, S. T. A valoração das paisagens protegidas de Diamantina (MG): premissa para o turismo cultural. Caderno de Geografia, v.22 (n.38, pp. 1-13). Disponível em: $</ 4376$ "http://periodicos.pucminas.br/index.php/\%20geografia/article\%20/viewFile/3149/4376"/31 49/4376>. Acessado em: 19 de Junho de 2018. 